\section{ARF HIKE}

\section{GDC DEFEATED BUT ARF HIKE STANDS}

In a landmark judgement on 18 December 2014, the General Dental Council (GDC) was found to have acted unlawfully on setting professional fees.

The British Dental Association (BDA) initiated Judicial Review proceedings to prevent the regulator implementing a $£ 15$ million increase to the fees levied on the dental profession. The consultation behind the annual retention fee (ARF) rise has been deemed unlawful, but the judge declined to reverse the fee rise, their counsel citing the risk of 'administrative chaos' at the GDC.

Mick Armstrong, Chair of the BDA, said: 'We regret that it came to this, but there was so much more at stake here than just fees. We've seen patients and practitioners left in limbo for over 18 months when complaints are raised, and hearings with an average price tag of $£ 78,000$. We had to take action because health professionals should not have to subsidise failure at their regulator.

'This super-sized fee rise still stands, and now serves as a monument to the failures of health regulation. This case has revealed that a regulator, unaccountable to government, can be found to have acted unlawfully but still walk away with its ill-gotten gains. We are now looking to the Government to act.'

The BDA has written to the Department of Health to outline the worrying implications of this case.

\section{The GDC responds}

Responding to the outcome of the Judicial Review, the GDC said that it recognised that the judge found there was a procedural error in the ARF level consultation. However, it said that it was pleased that Mr Justice Cranston also recognised that the GDC 'has to be properly funded in order to carry out its duties to protect the public and that the error was not serious enough to require him to quash the consultation and the new fee' The GDC reminded dentists of the 31 December fee deadline for 2014 in the same statement.

\section{FGDP (UK): Fitness to practise} processes must be changed

The Faculty of General Dental Practice (UK) said that the GDC must review its decision to raise the ARF given that their consultation was found to be unlawful, and said that it would be prudent for the GDC to change fitness to practise (FtP) processes.

Local Dental Committees: A pyrrhic victory for the profession?

On behalf of the coalition of Local Dental Committees (LDCs), Ian Gordon, Chair of North Yorkshire LDC, said: 'This could be seen as a pyrrhic victory for the profession in so far as GDC costs will be met by fees paid to the GDC by dentists - however, it was always about more than money and this result must be a springboard to substantive change in how the profession is regulated. It has to be remembered that despite the ARF increase the BDA won the arguments'.

\title{
BDA WINTER LECTURE
}

The BDA/BDJ Winter Lecture is now available for members to view online.

At the 2014 lecture, which took place on 10 December, Dr Michele Barbour spoke on 'Dental materials today and tomorrow', discussing technologies available and in the pipeline and what really matters when it comes to dental restoratives. To view the lecture, visit https://www. bda.org/winterlecture.

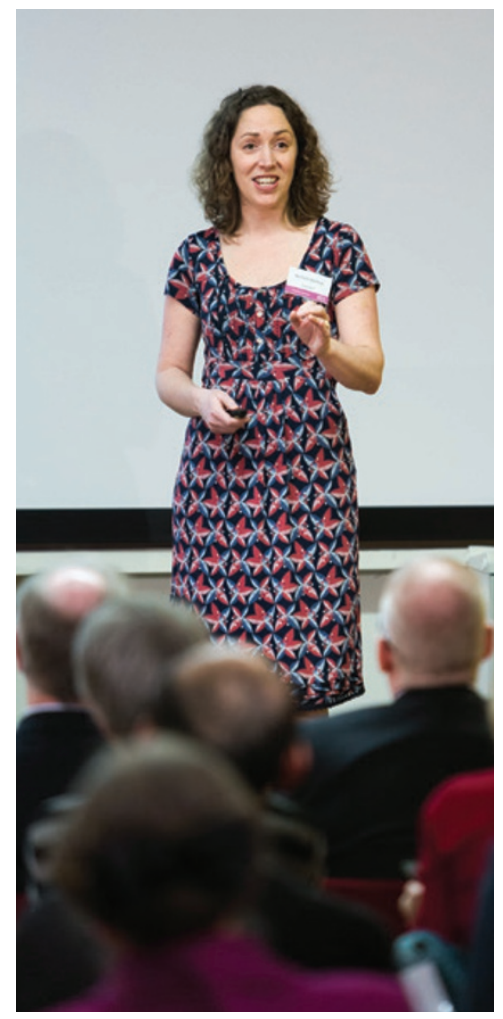

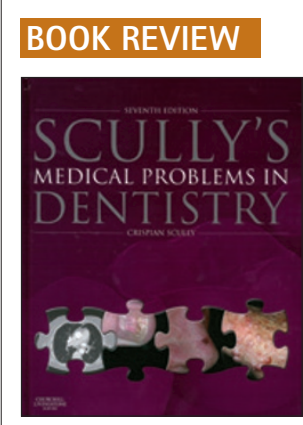

\section{SCULLY'S MEDICAL PROBLEMS IN DENTISTRY, 7TH EDITION \\ C. Scully \\ Churchill Livingstone \\ price 669.99 ; pp 832 ISBN 9780702054013}

The seventh edition of this recognised and established text covers in detail medical disorders and their impact on dental practice. It aims to equip the dentist with the knowledge to communicate with patients effectively and manage their medical and dental needs holistically, as well as the ability to recognise the need for advice and collaboration with our medical colleagues where necessary.

The book is divided into sections covering 'general medicine', 'organ systems medicine', 'other systems medicine' and 'other health issues' ranging from age and gender issues to substance dependence and health promotion.

The author approaches the subject matter consistently, with each sub-section covering the general aspects, clinical features, general management and dental aspects of medical conditions. This provides a logical, clear format for the reader to refer to.

General medical as well as surgical conditions are explored in detail and their relevance to the dental team discussed. Less frequently encountered, but nonetheless relevant, issues are also included which makes for a thorough and comprehensive edition. Updates in pharmacology, biological therapies, dental material hypersensitivity and alternative medicine set this text apart from previous editions.

The depth and breadth of the topics covered allow the general dentist as well as the specialist dentist to maintain and develop their understanding of general medical and surgical conditions, as well as providing dental students with a reliable and clear resource for learning.

The use of tables, flowcharts and figures provide diagrammatic support for the text and allow the salient points to be accessible at a glance. Provision of appendices at the end of each chapter along with suggestions of useful websites supplement the text and provide the reader with up to date online references and e-Learning resources.

The text fulfils its purpose entirely in providing the dental team with a thorough grounding in the dental-medical interface and the safe delivery of dental care.

R. HAMAD 